\title{
Posterior Fossa Dural Arteriovenous Fistulas with Subarachnoid Venous Drainage: Outcomes of Endovascular Treatment
}

\author{
(D). Détraz, DK. Orlov, (D) V. Berestov, (D). Borodetsky, DA. Rouchaud, DL.G. de Abreu Mattos, and (D) Mounayer
}

\begin{abstract}
BACKGROUND AND PURPOSE: Dural AVFs located in the posterior fossa are a rare entity. The objectives of the study were to analyze the anatomy of dural AVFs, their endovascular treatment strategies, and clinical outcomes.
\end{abstract}

MATERIALS AND METHODS: Two centers retrospectively selected patients treated between January 2009 and June 2018 having posterior fossa dural AVFs. We collected patient demographics, clinical presentation, arterial and venous outflow anatomy of the dural AVFs, and treatment outcomes.

RESULTS: Twenty-six patients treated endovascularly for posterior fossa dural AVFs, type III, IV, or V, were included. One hundred percent of the dural AVFs were occluded. A transarterial approach was performed in 23 dural AVFs (88.5\%); a combined transarterial and transvenous approach, for 2 dural AVFs (7.7\%); and a transvenous approach alone, for 1 dural AVF (3.8\%). The middle meningeal artery was the most common artery chosen to inject embolic liquid (46\%, 12/26). Procedure-related morbidity was $15.4 \%$ at 24 hours, $7.7 \%$ at discharge, and $0 \%$ at 6 months. Procedure-related mortality was $0 \%$.

CONCLUSIONS: Endovascular treatment offers high occlusion rates for posterior fossa dural AVFs with low morbidity and mortality rates. The arterial approach is the first-line preferred approach, even if a transvenous or combined approach would be a safe and effective option for patients with favorable anatomy.

ABBREVIATIONS: APA = ascending pharyngeal artery; $\mathrm{dAVF}=$ dural AVF; $\mathrm{MHT}=$ meningohypophyseal trunk; $\mathrm{MMA}=$ middle meningeal artery; NAEL = nonadhesive embolic liquid; PMA = posterior meningeal artery

D ural AVFs (dAVFs) are a rare pathology, accounting for $10 \%-15 \%$ of all intracranial vascular shunts. ${ }^{1}$ dAVFs of the posterior fossa are defined as intracranial direct shunts involving the tentorium and the dura that covers the remainder of the posterior fossa. ${ }^{2}$

On the basis of their drainage, dAVFs of the posterior fossa can be divided into 2 entities: benign fistulas, ${ }^{3}$ draining into a sinus, and those with a high risk of bleeding, with a subarachnoid venous drainage. If one excluded shunts of the transverse and sigmoid

\footnotetext{
Received April 19, 2019; accepted after revision June 19.

From the Service de Neuroradiologie Interventionnelle et Diagnostique (L.D.), Centre Hospitalier Universitaire de Nantes-Hopital Laennec, Saint-Herblain, France; Department of Neurosurgery (K.O., V. Berestov), E. Meshalkin National Medical Research Center of the Ministry of Health of the Russian Federation, Novosibirsk, Russia; Service de Radiologie (V. Borodetsky, A.R.. L.G.d.A.M., C.M.), Neuroradiologie Interventionnelle, Centre Hospitalier Universitaire de Limoges, Limoges, France; and CNRS (A.R., C.M.), XLIM, UMR 7252, University of Limoges, Limoges, France.

Please address correspondence to Lili Détraz, MD, Service de Neuroradiologie interventionnelle et Diagnostique, HGRL, CHU de Nantes, 44000 Nantes; e-mail: lili.detraz@gmail.com

三 Indicates article with supplemental on-line tables.

http://dx.doi.org/10.3174/ajnr.A6140
}

sinuses, posterior fossa fistulas are the most dangerous fistulas due to their cortical drainage at risk of rupture and their eloquent location. ${ }^{3,4}$

Due to their rarity, only a few studies ${ }^{2-4}$ have described the anatomic settings, clinical presentation, and endovascular management of posterior fossa dAVFs. Hence, we reviewed dAVFs located in the posterior fossa with subarachnoid venous drainage from 2 centers (University Hospital of Limoges, France and National Medical Research, Center of the Ministry of Health of the Russian Federation, Novosibirsk, Russia), all treated by an endovascular approach. We analyzed their anatomy and clinical presentation and discussed their endovascular treatment.

\section{MATERIALS AND METHODS Data Collection}

Data regarding patient demographics, baseline clinical presentations, embolization techniques, and follow-up outcomes were collected in prospective data bases of dural arteriovenous shunts treated by an endovascular approach at 2 interventional neuroradiology centers from January 2009 to June 2018. During this period, every patient presenting at the hospital with a posterior fossa 
dAVF with subarachnoid venous drainage, ruptured or not, was treated by a multidisciplinary neurovascular staff (neurosurgeons and neuroradiologist). Cases of posterior fossa dAVFs with subarachnoid venous drainage have been retrospectively identified from those data bases for this specific study. A retrospective analysis of the patient record, neuroimaging, and follow-up was performed by 2 investigators in each center. At least 1 of the 2 investigators was not involved into the patient's treatment. Investigators had at least 2 years of experience in interventional neuroradiology. In case of discrepancy, the investigators reviewed the cases together to reach consensus.

\section{Patient Selection}

All cases were diagnosed with initial MR imaging or CT angiography and further confirmed and analyzed by selective DSA. Initial DSA included a complete angiography (bilateral internal and external carotid arteries, and bilateral vertebral artery).

Inclusion criteria were endovascularly treated patients with ruptured and unruptured dAVFs, with a dural shunt located in the posterior fossa and subarachnoid venous drainage. Exclusion criteria were dAVFs directly draining into the sinus.

\section{Endovascular Treatment Protocol}

In each center, the therapeutic strategy was defined by a multidisciplinary neurovascular team. All the selected patients had been treated endovascularly, under general anesthesia. Procedures were performed in a biplane, flat panel angiographic suite (Allura Xper FD20; Philips Healthcare, Best, the Netherlands). Arterial vascular access was achieved by a transfemoral approach using a $6 \mathrm{~F}$ catheter. When venous access was needed, a transjugular or transfemoral approach was used. For each patient, 3000-5000 IU of heparin was administered intravenously at the beginning of the intracranial catheterization.

Nonadhesive embolic liquid (NAEL) and adhesive embolic liquid agents were used. NAELs used were the following: Onyx (Covidien, Irvine, California), SQUID (http://medcinpharma. com/products-solutions/emboflu/), or Precipitating Hydrophobic Injectable Liquid (PHIL; MicroVention, Tustin, California). The adhesive embolic liquid used was Glubran Tiss (Glubran ${ }^{\circledR}$, GEM, Viareggio, Italy).

\section{Clinical and Imaging Follow-Up}

Every patient underwent full clinical and neurologic evaluation by the senior neuroradiologist in charge, before the treatment, at awakening, at discharge, and 6 months after the endovascular procedure. The 6-months evaluation was usually followed by DSA. If DSA was not performed, patients underwent MR imaging. The mRS was assessed before the treatment, at discharge, and at 6 months. A stable or improved mRS between pretreatment and 6-month follow-up was considered a good clinical outcome.

\section{RESULTS}

\section{Patient Baseline Characteristics}

Of the 198 dAVFs treated in the 2 centers, 26 patients $(13.1 \%)$ presented with posterior fossa dAVFs with subarachnoid venous drainage and were included in this study. The mean age was $54 \pm 15$ years (range, 23-80 years) with $80.7 \%$ men $(21 / 26)$.

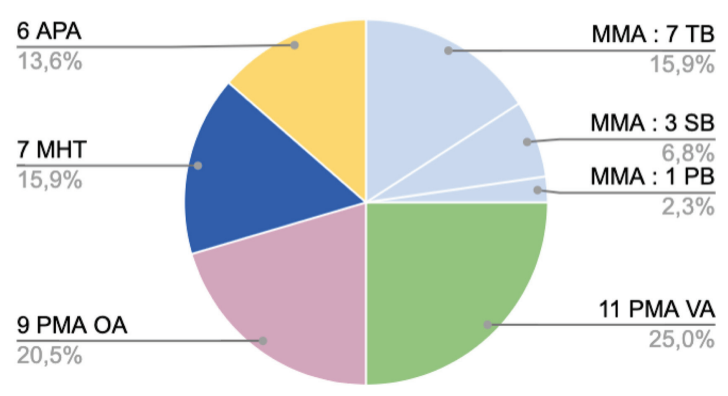

FIG 1. Arterial feeders of the dAVFs and number of dAVF fed by a given artery. Twenty-two of $26 \mathrm{dAVFs}$ had multiple feeders. OA indicates occipital artery; PB, petrous branch; TB, tentorial branch; SB, squamous branch; VA, vertebral artery.

Eight patients $(30.7 \%)$ presented with intracranial hemorrhage (On-line Table 1).

According to the Cognard classification, ${ }^{5} 10 \mathrm{dAVFs}(38.5 \%)$ were type III, 10 were type IV (38.5\%), and 6 were type V (23.1\%).

Clinical symptoms leading to the diagnosis were headache (9 cases, $34.6 \%$ ), cerebellar syndrome (4 cases, $15.4 \%$ ), hemiparesis ( 2 cases, $7.7 \%$ ), myelopathy ( 4 cases, $15.4 \%$ ), acute cervical pain ( 1 case, $3.8 \%$ ), and pulsatile tinnitus ( 1 case, $3.8 \%$ ). Five cases (19.2\%) were incidental findings.

\section{Location and Angioarchitecture}

All dAVFs were fed by a meningeal branch of the external carotid artery. Multiple arterial feeders were observed in $84.4 \%(22 / 26)$ of cases, with a bilateral supply in $61.5 \%(16 / 26)$. The most common feeding artery was the middle meningeal artery (MMA) (11 cases, 42.3\%; 7 from a tentorial branch, 3 from a squamous branch, 1 from a petrosal branch); then, the posterior meningeal artery (PMA) arising from the vertebral artery (11 cases, $42.3 \%$ ); the PMA from occipital artery ( 9 cases, $34.6 \%$ ); the medial tentorial branch of the meningohypophyseal trunk (MHT) (7 cases, $26.7 \%$ ); and the ascending pharyngeal artery (APA) (6 cases, $23.1 \%$; 3 from the hypoglossal branch and 3 from the jugular branch) (Fig 1 and On-line Table 1).

Seven dAVFs with a petrosal location presented with a shunt into the superior petrosal vein: Five dAVFs had a venous outflow into the basal vein, $1 \mathrm{dAVF}$ had an outflow into the tentorial lateral sinus, and $1 \mathrm{dAVF}$, into the perimedullary veins (On-line Tables 1 and 2).

Four dAVFs located on the free edge of the tentorium presented with a shunt into the tectal vein with a venous outflow into the torcular. All were supplied by a meningeal branch of the superior cerebellar artery with different secondary supplies, with branches arising from the internal carotid artery or from the PMA (On-line Tables 1 and 2).

Eight dAVFs with a posterior tentorial location presented with a shunt into the declival vein with an outflow into the cerebellar veins (On-line Tables 1 and 2).

Two dAVFs also presented with a posterior tentorial location but with a shunt into the inferior cerebellar vein and a lateral tentorial sinus outflow (On-line Tables 1 and 2).

Six dAVFs had a perimedullary outflow: Five dAVFs were located on the foramen magnum with a shunt into the lateral medullary vein and without any MMA feeding, whereas $1 \mathrm{dAVF}$, de- 


\begin{tabular}{|c|c|c|c|c|c|c|c|}
\hline & \multicolumn{5}{|c|}{ Arterial Approach } & \multirow[b]{2}{*}{$\begin{array}{l}\text { Combined } \\
\text { Approach }\end{array}$} & \multirow[b]{2}{*}{$\begin{array}{l}\text { Venous } \\
\text { Approach }\end{array}$} \\
\hline & Onyx 18 & PHIL & $\begin{array}{l}\text { Onyx } 18+ \\
\text { Glubran }\end{array}$ & Glubran & SQUID & & \\
\hline No. of dAVFs treated & & & 23 & & & 2 & 1 \\
\hline No. of sessions & 17 & 3 & 2 & 2 & 2 & 3 & 1 \\
\hline Complications (No. of cases) & 3 & 0 & 0 & 1 & 0 & 0 & 0 \\
\hline
\end{tabular}

the meningeal branch of the SCA and by different accessory supplies from the PMA or the MHT. Hence, embolization through the meningeal branch of the SCA was the first option $(50.0 \%$ of the cases) when the navigation and Onyx reflux were acceptable. For 1 case, due to incomplete occlusion and arterial navi-
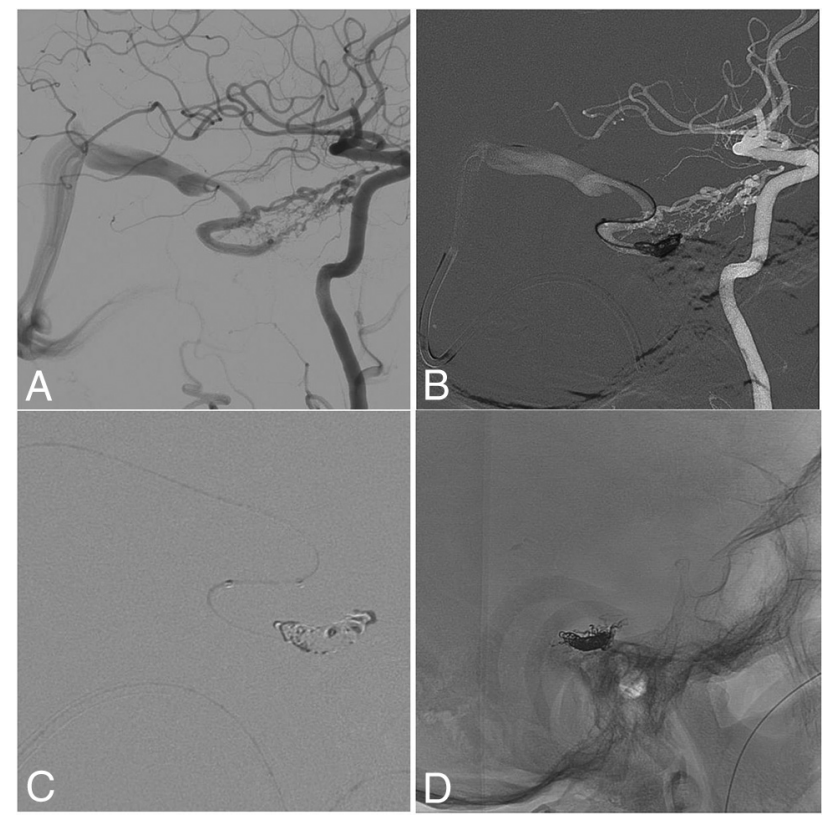

FIG 2. Transvenous approach. Arteriography of a petrosal dAVF with petrosal outflow, fed by the recurrent tentorial branch of the inferolateral trunk and a posterior meningeal branch, draining into the internal temporal vein. Retrograde catheterization of the straight sinus via the jugular golf and lateral sinus. Two Echelon 10 microcatheters (Covidien) were navigated to the foot vein located on the internal temporal vein. By means of 1 microcatheter, platinum coils were rolled; then Onyx 18 was injected through the second microcatheter. The dAVF was totally cured at the end of the intervention. A, Lateral initial angiogram. $B$, Transvenous coiling. $C$, Transvenous Onyx injection. $D$, Cast of Onyx and coils.

scribed above, had a petrosal location with a shunt into the superior petrosal vein, fed by the tentorial branch of MMA (On-line Tables 1 and 2).

\section{Endovascular Treatment Strategies}

A transarterial approach was performed in 23 dAVFs (88.5\%); a combined transarterial and transvenous approach, in 2 patients (7.7\%); and a transvenous approach alone, in 1 patient $(3.8 \%)$ (On-line Tables 1 and 2 and Table). During the selected period, $100 \%$ of the dAVFs were totally occluded. Twenty-two $(84.6 \%)$ dAVFs were totally occluded with a single session; 3 dAVFs, (7.7\%) after 2 sessions; and 1 (3.8\%), after 3 sessions. Details are provided in the Table. No patients had an operation.

Regarding dAVFs draining into the basal vein, MMA embolization was the first option in $80.0 \%$ of cases, even if the MHT/ infero-lateral trunk was the principal feeder. One dAVF was occluded using a single transvenous approach due to the narrowed caliber of the main feeding artery and the risk of reflux into the ICA. Details are provided in Fig 2.

dAVFs with a tectal shunt and a torcular outflow were fed by gation difficulties, embolization was completed by a transvenous approach with a pressure cooker technique using coils and NAEL to increase the ability to push more NAEL and control the flow.

Concerning dAVFs draining into the cerebellar cortical veins, the MMA was the most frequent feeder (75.0\%), and the embolization via the MMA was the first option when possible ( 5 cases, $62.5 \%$ ) (Fig 3). The PMA (3 cases, 37.5\%) and transosseous branches ( 1 case, $12.5 \%$ ) were the second option due to the risk of ischemia in case of reflux into the vertebral artery and navigation difficulties.

For dAVFs draining into the lateral tentorial sinus, a transarterial approach via the MMA was the first option when possible. In 1 case, a complementary transvenous approach through the tentorial sinus was also performed because of the partial occlusion via injection of embolic liquid through a narrow MMA. Occlusion was total.

For dAVFs draining into the perimedullary veins, a venous approach was not possible. Regarding the foramen magnum fistulas, despite the frequency of anastomosis in this area, 3 cases $(60.0 \%)$ of dAVFs were treated via the PMA. For the petrosal location, the MMA was chosen (Fig 4).

\section{Clinical and Angiographic Outcomes}

Treatment-related morbidity was observed in 4 patients (15.4\%), including 2 with complete recovery in $<24$ hours. The 2 other patients had a full recovery at 6-month follow-up. Transient symptoms presented were a fourth cranial nerve palsy after NAEL embolization and hemiparesis after reflux of NAEL into the vertebral artery. The 2 major complications were hydrocephaly due to mass effect after a venous thrombosis and superior cerebellar ischemia due to a NAEL arterial reflux (On-line Table 1). We report no complications with transvenous or combined procedures. Thus, procedure-related morbidity at 24 hours was $15.5 \%$; at discharge, it was $7.7 \%$; and at 6 months, it was $0 \%$. Procedurerelated mortality was $0 \%$.

Four patients were lost to follow-up, for whom the mRS at discharge was zero. Compared with the clinical situation at the time of diagnosis, every patient had a stable or improved clinical situation at 6 months (Fig 5). All of them achieved independence $(\mathrm{mRS}<2)$ at 6 months or at discharge versus $80.0 \%$ at the time of the diagnosis.

Twenty-two patients (84.6\%) underwent a control angiography at 6 months, which showed permanent occlusion for each of them.

\section{DISCUSSION}

\section{Treatment Considerations and Classification}

When intervention is indicated, the cornerstone of dAVF treatment is the disconnection of the vein foot. Proximal draining 

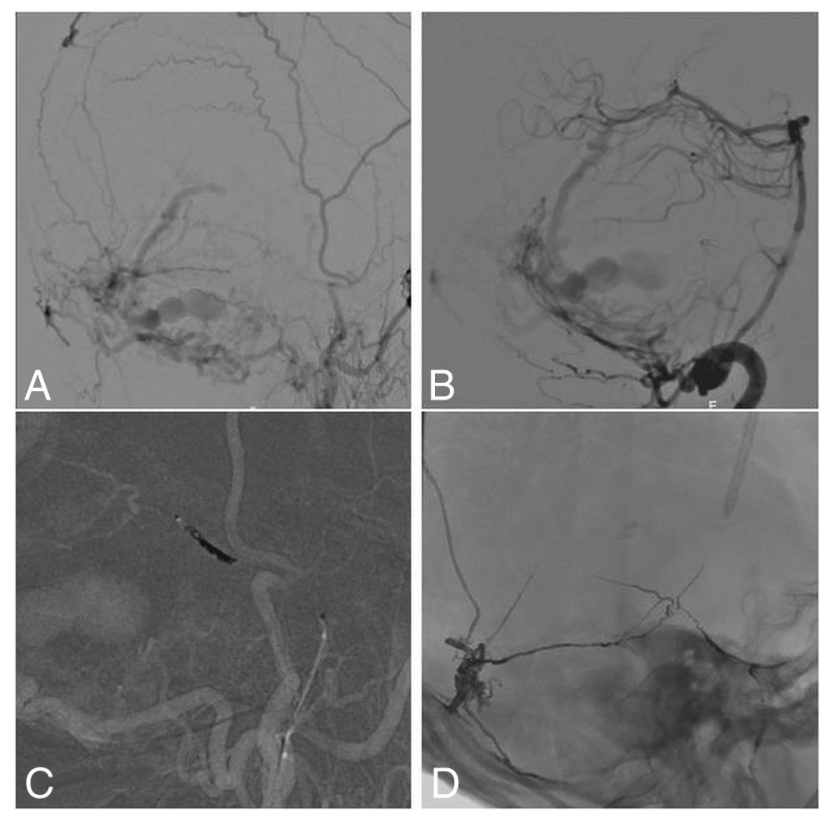

FIG 3. Transarterial approach. Arteriography of a ruptured dAVF with a shunt located in the declival vein and venous outflow into the cerebellar veins, fed by the PMA of the vertebral artery, transosseous branches of the occipital artery and squamous branch of the MMA. The MMA was catheterized; platinum coils were rolled into the MMA to improve NAEL penetration, and then, NAEL was injected. $A$, Lateral initial angiogram via the external carotid artery. $B$, Lateral initial angiogram via the vertebral artery. C, Coils with the pressure cooker technique in the MMA. D, Final cast of Onyx and coils.

veins must be occluded at the end of the treatment. ${ }^{6}$ Due to their rarity, endovascular treatment of posterior fossa dAVFs has been less often described. Nevertheless, the arterial approach is the most common one even if a transvenous or combined approach can be a safe and effective option. ${ }^{7,8}$ As described in the literature, $^{7}$ in our series the transarterial route was the first-line approach. However, regarding the 3 patients treated by a transvenous approach, alone or combined, we detected no clinical complications, and the mRS was stable or improved at 6 months for those patients. Hence, even if we cannot support any conclusion with such a small number of patients, the transvenous approach could be an option for some selective cases.

Furthermore, in agreement with the literature, ${ }^{6,9,10}$ the MMA was the most commonly selected artery to navigate to the shunt, even if it was not the main feeding artery, because of the less tortuous route and the lower rate of dangerous anastomosis. We report 2 main complications: extended venous thrombosis causing hydrocephaly and cerebellar ischemia unrelated to the MMA navigation.

In the present series, complication rates linked to the procedure were low. However, the complication rates reported in the literature were even lower. Indeed, Maimon et $\mathrm{al}^{6}$ reported a complication rate of $5.8 \%$, and Cognard et al, ${ }^{11}$ a rate of $6.7 \%$. However, those rates do not specifically concern posterior fossa dAVFs but all dAVFs with cortical venous drainage, including dAVFs that are considered safer to treat. Besides, Zhou et al, ${ }^{4}$ in a series of 5 tentorial dAVFs, reported 1 complication (20\%) due to a cerebellar infarctus, whereas Motebajane and Choi, ${ }^{12}$ in a series of 12

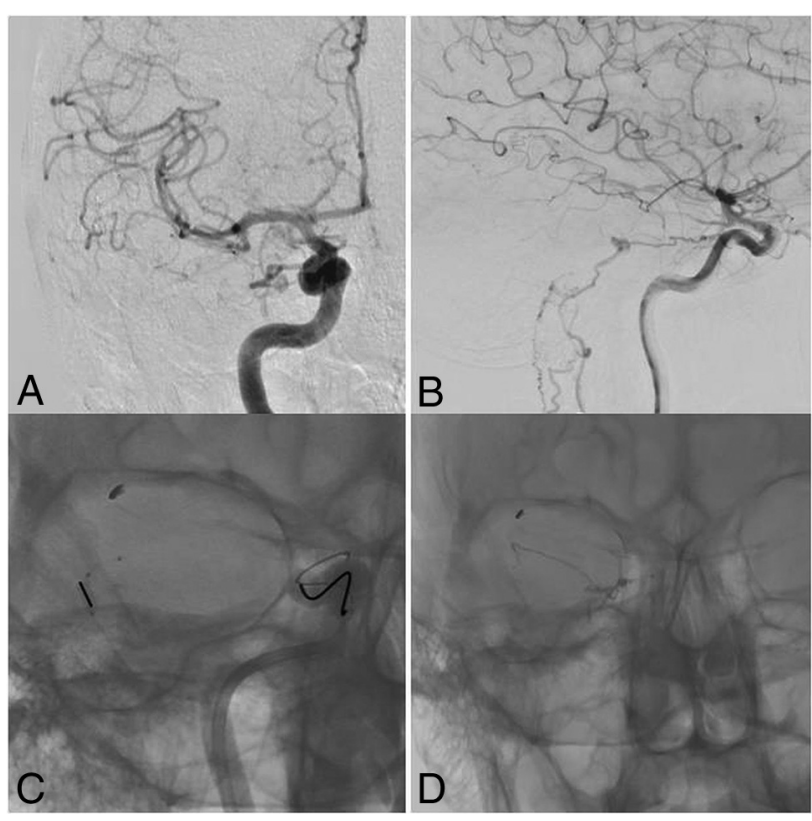

FIG 4. Double balloons with a pressure cooker technique. Arteriography of an unruptured petrosal dAVF, fed by the medial tentorial branch of the MHT and a tentorial branch of the MMA, draining into superior petrosal vein with an outflow into the perimedullary veins. A balloon pressure cooker technique was used. A Scepter XC $4 \times 11$ balloon (MicroVention, Tustin, California) was inflated in the MMA to improve the Onyx injection, while protecting the carotid siphon with a Copernic balloon (Balt Extrusion, Montmorency, France). While both balloons were inflated, Onyx 18 was injected in a single session using a Marathon microcatheter (Covidien). Total occlusion of the shunt was noted on the final angiography. A, Antero-posterior initial angiogram. $B$, Lateral initial angiogram. $C$, Balloon pressure cooker technique in the MMA with the balloon-protecting device in the ICA. D, Final cast of Onyx.

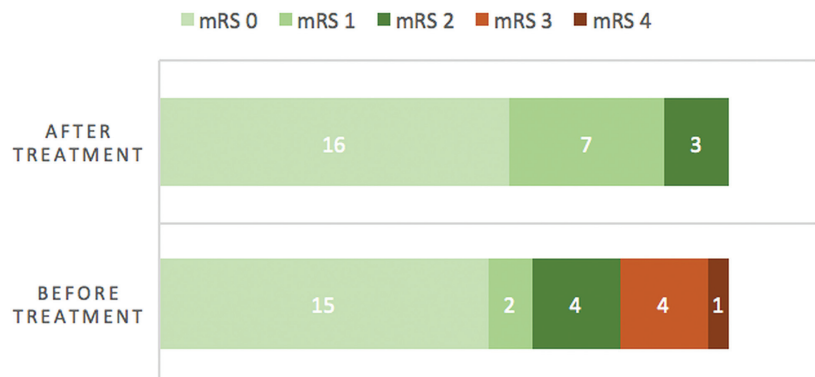

FIG 5. mRS before treatment at the time of the diagnosis and 6 months after treatment when available, or at discharge if not.

dAVFs of the foramen magnum treated with $n$-BCA, reported no complications as Liang et $\mathrm{al}^{13}$ in a series of $5 \mathrm{dAVFs}$ of the foramen magnum treated with Onyx. Besides, tentorial fistulas are more challenging because there is usually a dural supply from both the internal and external carotid arteries, increasing the procedural risk of intracranial embolic events. ${ }^{9}$ Furthermore, because the venous drainage pattern is linked to the clinical symptoms, ${ }^{14,15}$ this slightly higher complication rate regarding fossa posterior fistulas might be linked to the specificity of posterior fossa drainage. Likewise, posterior fossa fistulas are located in a very eloquent zone.

Finally, the complication rate of the present series might also be linked to a more intensive endovascular treatment because 
$100 \%$ of the dAVFs were occluded, whereas Maimon et $\mathrm{al}^{6}$ reported a rate of $88.3 \%$, and Cognard et al, ${ }^{11}$ a rate of $80 \%$ of total occlusion.

\section{Anatomic Considerations and Classification}

We analyzed 26 dAVFs of the posterior fossa with infratentorial venous drainage. Because of the importance of venous drainage in the clinical presentation, ${ }^{15}$ special attention should be given to the venous outflow to improve the understanding of the shunt and the flow. Venous outflow can be defined according to the main draining vein at the level of the shunt. Thus, based on their venous outflow, cases have been classified into 5 groups, considering the shunt, the arterial feeders, and the treatment strategy.

The 5 groups noted were the following: group 1, vein outflow into the basal vein; group 2, vein outflow into the torcular; group 3 , vein outflow into the cerebellar cortical vein; group 4, vein outflow into the lateral tentorial sinus; and group 5, vein outflow into the perimedullary venous plexus.

Other classifications exist but are not adapted to the endovascular approach because they are not specifically based on the outflow. Indeed, Lawton et $\mathrm{al}^{16}$ established a very detailed classification dividing 31 tentorial dAVFs into 6 groups. Nevertheless, this classification is anatomic and does not examine the venous outflow pattern. It is mainly to prepare the surgical access but is not adapted for an endovascular approach. There is another classification based on the location of the shunt and not on the outflow, thus including a posterior fossa shunt with occasionally supratentorial drainage. ${ }^{17}$ Hence, the proposed classification is more adapted to the endovascular approach and based on venous outflow, which is the most clinically impactful. ${ }^{15}$ However, due to the rarity of the cases, this classification has to be strengthened by further studies including more patients.

All of the dAVFs draining into the basal vein were petrosal and had a venous shunt into the superior petrosal vein. One other petrosal dAVF drained into the tentorial sinus, and another petrosal dAVF drained into perimedullary veins. Hence, for petrosal dAVFs, the anatomic location of the shunt did not predict the outflow and thus the symptoms, enhancing the need for a classification considering the venous outflow. In fact, our results were consistent with the pattern of drainage of the petrosal dAVF, which was described by $\mathrm{Li}$ et $\mathrm{al}^{18}$ and Matsushima et al. ${ }^{19}$ They classified petrosal dAVFs into 4 groups based on the draining area: the posterior mesencephalic group, anterior pontomesencephalic group, petrosal group, and tentorial group. They showed that all patients from the posterior mesencephalic group and some patients from the pontomesencephalic group had supratentorial drainage via a connection to the basilar vein. However, in the present series, we focused only on infratentorial drainage, so we do not present any pontomesencephalic dAVFs in our series.

Regarding the perimedullary drainage, the 5 dAVFs with a shunt into the lateral medullary vein were located on the foramen magnum and fed by the PMA of the vertebral artery or the APA as classically described in the literature. ${ }^{3,12}$

\section{Limitations}

Limitations should be noted in the present series. First, it is a retrospective analysis with inherent bias due to this method. Second, the cohort is relatively small because posterior fossa dAVFs are rare, and patients were not randomized into transarterial, transvenous, or combined approaches, which does not allow comparison among the different endovascular approaches.

Finally, due to their rarity, not many studies focusing on dAVFs of the posterior fossa can be found in the literature. To our knowledge, our series is the largest in the literature specifically concerning dAVFs of the posterior fossa.

\section{CONCLUSIONS}

dAVFs of the posterior fossa with subarachnoid venous drainage are rare and difficult to treat. Special attention should be given to the venous outflow to understand the pathology and analyze the therapeutic procedure. An arterial approach was the most common. A venous approach, isolated or combined, could also to be safe and successful in some selected cases; additional data are needed regarding this approach.

\section{ACKNOWLEDGMENTS}

We acknowledge Suzana Saleme and Vladimir Boretsky for their support.

\section{REFERENCES}

1. Newton TH, Cronqvist S. Involvement of dural arteries in intracranial arteriovenous malformations. Radiology 1969;93:1071-78 CrossRef Medline

2. Newton TH, Weidner W, Greitz T. Dural arteriovenous malformation in the posterior fossa. Radiology 1968;90:27-35 CrossRef Medline

3. Pierot L, Chiras J, Meder JF, et al. Dural arteriovenous fistulas of the posterior fossa draining into subarachnoid veins. AJNR Am J Neuroradiol 1992;13:315-23 Medline

4. Zhou LF, Chen L, Song DL, et al. Tentorial dural arteriovenous fistulas. Surg Neurol 2007;67:472-81; discussion 481-82 CrossRef Medline

5. Cognard C, Gobin YP, Pierot L, et al. Cerebral dural arteriovenous fistulas: clinical and angiographic correlation with a revised classification of venous drainage. Radiology 1995;194:671-80 CrossRef Medline

6. Maimon S, Nossek E, Strauss I, et al. Transarterial treatment with Onyx of intracranial dural arteriovenous fistula with cortical drainage in 17 patients. AJNR Am J Neuroradiol 2011;32:2180-84 CrossRef Medline

7. Lee SK, Hetts SW, Halbach V, et al; Standard and Guidelines Committee for the Society of Neurointerventional Surgery. Standard and guidelines: intracranial dural arteriovenous shunts. J Neurointerv Surg 2017;9:516-23 CrossRef Medline

8. Wong GK, Poon WS, Yu SC, et al. Transvenous embolization for dural transverse sinus fistulas with occluded sigmoid sinus. Acta Neurochir (Wien) 2007;149:929-35; discussion 935-36 CrossRef Medline

9. Kortman H, Bloemsma G, Boukrab I, et al. Treatment of cranial dural arteriovenous fistulas with exclusive cortical venous drainage: a single-center cohort of 35 patients. Interv Neuroradiol 2017;23:661-65 CrossRef Medline

10. Stiefel MF, Albuquerque FC, Park MS, et al. Endovascular treatment of intracranial dural arteriovenous fistulae using Onyx: a case series. Neurosurgery 2009;65(6 Suppl):132-39; discussion 139-40 CrossRef Medline

11. Cognard C, Januel AC, Silva NA Jr, et al. Endovascular treatment of intracranial dural arteriovenous fistulas with cortical venous

AJNR Am J Neuroradiol 40:1363-68 Aug 2019 www.ajnr.org

1367 
drainage: new management using Onyx. AJNR Am J Neuroradiol 2008;29:235-41 CrossRef Medline

12. Motebejane MS, Choi IS. Foramen magnum dural arteriovenous fistulas: clinical presentations and treatment outcomes: a case-series of 12 patients. Oper Neurosurg (Hagerstown) 2018;15:262-69 CrossRef Medline

13. Liang G, Gao X, Li Z, et al. Endovascular treatment for dural arteriovenous fistula at the foramen magnum: report of five consecutive patients and experience with balloon-augmented transarterial Onyx injection. J Neuroradiol 2013;40:134-39 CrossRef Medline

14. Houser OW, Baker HL Jr, Rhoton AL Jr, et al. Intracranial dural arteriovenous malformations. Radiology 1972;105:55-64 CrossRef Medline

15. Lasjaunias P, Chiu M, ter Brugge K, et al. Neurological manifesta- tions of intracranial dural arteriovenous malformations. J Neurosurg 1986;64:724-30 CrossRef Medline

16. Lawton MT, Sanchez-Mejia RO, Pham D, et al. Tentorial dural arteriovenous fistulae: operative strategies and microsurgical results for six types. Neurosurgery 2008;62(3 Suppl 1):110-24; discussion 124-25 CrossRef Medline

17. Byrne JV, Garcia M. Tentorial dural fistulas: endovascular management and description of the medial dural-tentorial branch of the superior cerebellar artery. AJNR Am J Neuroradiol 2013;34:1798804 CrossRef Medline

18. Li J, Ren J, Du S, et al. Dural arteriovenous fistulas at the petrous apex. World Neurosurg. 2018;119:e968-76 CrossRef Medline

19. Matsushima K, Matsushima T, Kuga Y, et al. Classification of the superior petrosal veins and sinus based on drainage pattern. Neurosurgery 2014;10(Suppl 2):357-67; discussion 367 CrossRef Medline 